\title{
Evaluating the impression of positive and negative affectivity on the implementation of impression management tactics
}

\author{
Mehdi Molaee Ghara*, Marjan Abdi, Fatemeh Alinaghi Langari and Hasan Danaee
}

Master Student of Payame Noor University, Iran

\begin{tabular}{l}
\hline C H R O N I C L E \\
\hline Article history: \\
Received January 5, 2013 \\
Received in revised format \\
2 April 2013 \\
Accepted 3 April 2013 \\
Available online \\
April 32013 \\
\hline Keywords: \\
Supplication tactic \\
Ingratiation tactic \\
Intimidation tactic \\
Negative affectivity \\
Positive affectivity
\end{tabular}

\begin{abstract}
A B S T R A C T
The present study investigates the relationship between positive and negative affectivity by the application of impression management tactics. A review on literature reveals positive affectivity has attracted less attention compared with negative affectivity. Investigated tactics in this study include supplication, ingratiation, and intimidation and threat. Results indicate that there was a positive and significant relationship between negative affectivity and application of threat, intimidation, and supplication tactics, while the relationship between negative affectivity and ingratiation tactic was negative and significant. The relationship between positive affectivity and application of threat and intimidation tactics was negative and significant. In addition, there was a positive and significant relationship between two variables of positive affectivity and application of ingratiation tactic. Furthermore, the relationship between two variables of positive affectivity and supplication tactic was negative.
\end{abstract}

\section{Introduction}

Impression management has absorbed significant attention among behavioral scientists originally introduced by Goffman (1959). According to Goffman (1959), people manage their desirable impressions on others in order to shape their own identities. Impression management is associated with behaviors used by people to control the image that others have of them (Rosenfeld et al., 1995) and it may also have negative connotations (Schlenker, 1980). This study investigates the relationship between affectivity, positive and negative and the applications of impression management tactics. On the basis of our interactions with the environment and the feedback that we receive, we adjust our objectives to acquire the desirable outcomes and minimize the undesirable ones (Schlenker, 1980). According to Schlenker (1980), these goals are partly obtained via impression management and there are different of studies indicating that people in organizations are often involved in impression management behaviors (e.g., Bozeman \& Kacmar, 1997; Leary \& Kowalski, 1990; Rosenfeld et al.,

*Corresponding author.

E-mail addresses: molaee1360@gmail.com (H. Molaee Ghara) 
1995). Experimental studies on impression management have been mostly focused either on the effective factors on the application of impression management tactics or on the relationship between impression management tactics and outcomes including promotions, performance assessment levels, career success called career development path. For instance, Wayne and Ferris (1990) reported that the application of ingratiation tactic by the employees had a positive and significant relationship with high scores in performance assessment by a supervisor. In addition, Judge and Bretz (1994) stated that the application of ingratiation tactic could contribute to higher levels of success in the careers of individuals, while the application of self-promotion leads to lower levels of success in careers.

The concept of impression tactics is implemented to explain the methods including bargaining, argumentation/reasoning, love and intimacy, assertiveness, coalitions, and other strategies, which influence on the decisions or behaviors of their colleagues, superiors, or subordinates (Kipnis et al., 1988). This study investigates the relationship between some of the causing factors and different kinds of applied impression management tactics. The effective factors on impression management included positive and negative affectivity and considered impression management tactics include ingratiation, supplication, intimidation, and threat. Each of the affectivities were associated with certain states and temperaments. Affectivity was an important variable of individual differentiation (personal characteristics) which has not been sufficiently considered in the research literature (Perrewé \& Spector, 2002). Research on the relationship between negative and positive affectivity and the application of impression management tactics have not advanced so much (Perrewé \& Spector, 2002), and these variables have been taken as control variable in most studies.

Regarding the necessity for conducting this study, it is enough to mention that, to the best of our knowledge, no studies in this field (impression management, affectivity and emotions) have been conducted in Iran. Thus, the present study helps us become familiar with the concepts and terms of impression management a great deal. The other reason was the contribution of the present study to the impression management literature, since research of this type has not been so advanced in the literature of impression management.

\subsection{Impression management tactics}

At the beginning of 1980s, some experts stated that individuals attempt to manage their desirable impressions on others (Goffman, 1959) and this may be performed either consciously or unconsciously (Schlenker, 1980). Individuals take these measures to change the views of others about themselves (Leary \& Kowalski, 1990). Impression management includes the behaviors, which are not part of individuals' job description. Impression management is misinterpreted more often associating a picture in people's mind on who aim at abusing others (Schlenker, 1980). According to Schlenker (1980), people try to "maximize their desirable outcomes and minimize their undesirable outcomes". Individuals make use of impression management tactics in order to impress the picture of their own in the minds of others.

Many of impression management tactics and measures have been discussed in the academic literature. Some studies have been devoted to this case, though there is little consensus about a detailed and comprehensive classification of impression management tactics (Mowday, 1978). Mowday (1978) investigated and studied the upward impression tactics such as threat, legitimate authority, persuasive arguments, awards, loving others, and clandestine manipulation. Kipnis et al. (1980) offered a classification of impression management tactics which included tactics of assertiveness, ingratiation, rationality, confirmation and sanction, exchange/interchange, appeal to higher authorities, blocking, and coalition. Most of the works by Bolino and Turnly (1999) are based on Jones and Pittman (1982) focused on tactics such as self-promotion, exemplification, supplication, ingratiation, and intimidation in their work. Some of these tactics are more assertive and they depend on the individual including exemplification and self-promotion while others are more flexible and 
rely on others such as ingratiation. Bolino and Turnly (1999) investigated some of these tactics, including ingratiation, supplication, intimidation, and threat. They categorized tactics into two categories: hard and soft. Ingratiation includes activities such as praising colleagues, loving others, and expressing interest in personal lives of people in the workplace. Ingratiation is only used for changing other people's image of the individual, while intimidation and threat tactics are assertive and they are implemented to change the activities and measures of others. In fact, compared with intimidation and threat tactics, ingratiation tactic is more flexible and moderate. Intimidation and threat tactics are related more to some controversial outcomes such as aggressive behavior toward colleagues when they interfere in our issues, making contacts to incur problems in our lives, and application of intimidation for making others help and support us. Supplication tactic includes passive behaviors including pretending to require to access others' help and sympathy, and pretending to misunderstand a task to avoid from performing an undesirable task (Bolino \& Turnly, 1999).

\subsection{Components of impression management tactics}

Although Schlenker (1980) states that impression management tactics may routinely and unconsciously be applied in the daily interaction of individuals, others believe that situational conditions such as ambiguity (Leary \& Kowalski, 1990) and personal characteristics could contribute to conscious and deliberate political behaviors and impression management (Ferris et al., 1989).

Research on the relationship between personal characteristics and different kinds of impression management tactics has not advanced so much (Ferris et al., 2002; Kacmar et al., 2004; KristofBrown et al. 2002). Experts who have investigated this relationship have considered the components of personal characteristics to be very diverse. For instance, Modey (1978) concluded that individuals who highly need power, make use of upward impression tactics. Modey also believed that political behaviors in the workplace had a substantial relationship with the intensity of the individuals' requirements and their personal perceptions of power. Vecchio and Sussmann (1991) stated that Machiavellism was substantially associated with the impression management tactic of blocking both as creator a barrier. They also investigated downward impression and concluded from their research that individuals with high rates of compatibility, in terms of social grounds, are more inclined to demagoguery. In addition, individuals with high need for power make use of utilitarian impression tactics, which could lead to exploit the subordinates. According to Bolino and Turnly (2003), selfcontrol and Machiavelli thinking influence different types of tactics used by individuals. They argued that individuals with high rates of self-control could be more sensitive towards the image that they present from themselves. That is the reason why they prevent from using supplication, intimidation and threat tactics. Instead, they usually implement positive tactics such as ingratiation, selfpromotion, and exemplification.

Cable \& Judge (2003) discovered the fact that individuals, who are less angry, apply a wide range of impression management tactics such as inspirational appeal, ingratiation, personal appeal, and exchange/interchange, because they have the necessary control and confidence to negotiate and interact with others. In addition, Caldwell and Burger (1997) stated that self-control and tending to high self-control in individuals had some relationship with the application of different impression management tactics such as rational persuasion and involvement. Van Iddekinge et al. (2007) investigated the relationship between impression management tactics implemented by job candidates and certain personal characteristics (Costa and McCrae, 1992) and reported that altruism aspect of agreeableness was negatively associated with defensive tactics and self-discipline aspect of morality/dutifulness) was positively associated with defensive tactics. Some scholars believe that personal characteristics make the individuals prone to implement certain tactics of impression management (Ferris \& Judge, 1991) and situational conditions activate certain personal tendencies (Tett \& Burnett, 2003; Tett \& Gutterman, 2000). Van Iddekinge et al. (2007) made a significant contribution to our understanding of different applications of impression management tactics, their studies, like that of Kristof-Brown et al. (2002). Studies on the relationship between positive and 
negative affectivity and various tactics of impression management have not advanced so much (Perrewé \& Spector, 2002) and these variables have often been used as control variable in the fulfilled research.

Among the fulfilled research, only one organizational investigation/study has studied the impact of situation and personal characteristics in the explanation of impression management tactics at workplace (Kacmar et al., 2004). However, this study has limited its investigation to ingratiation tactic. The mentioned study applied a combination of factors such as self-confidence, need for power, job involvement, and embarrassment and shyness. In addition, situational conditions normally influence the impression management tactics, which are used. For instance, factors such as role ambiguity, exchange/interchange of leader-member (Kacmar et al., 2004), hierarchical levels, accountability, and ambiguity (Fandt \& Ferris, 1990; Ferris et al., 1997) have been investigated in the research. Finally it should be added that in a study that was done by Christiansen et al. (1997) in this field, the relationship between the adjustment of organizational culture promoting the impression management and the degree of an individual's comfort and welfare.

In the following section, we state some of the components of impression management investigated in the research literature. These components are divided into two groups: 1) situational conditions, and 2) personal characteristics. This study investigates the effects of positive and negative affectivities on the impression management tactics. As it will be discussed below, positive and negative affectivities are part of personal characteristics.

\subsection{Situational conditions}

Some of the situational conditions that have been considered in the literature summarized as follows,

\subsubsection{Job Stressors}

Many people take stressors to be job related to events, conditions or requirements, which lead to perceptional pressure on the individual (Beehr, 1995). Job stressors include role conflict, role ambiguity and role overload. Role conflict is a perception, which results from conflicting demands between two or more sections, vague instructions, and insufficient resources to perform the task. Role ambiguity can be described as lack of certainty about mandates, responsibilities, and expectations of an individual (Rizzo et al., 1970). Role overload is specified as lack of time for performing the assigned tasks (Seashore et al., 1982). A meta-analysis of role ambiguity and conflict in workplace indicated that people generally believe that reacting against ambiguity and conflict create some issues such as decreased job satisfaction, decreased commitment to the organization, and lower performance, de-personalization, tension, fatigue, and tendency to leave one's job (Jackson \& Schuler, 1985; Örtqvist \& Wincent, 2006).

Ferris et al. (1989) reported that lack of certainty and ambiguity had a meaningful relationship with political behaviors. Mayes and Ganster (1988) stated that when people experience role stressors, they would not get involved in political behaviors if their organizational commitment were strong. Another investigation on upward tactics indicated a significant relationship between role conflict and more assertive and appealing tactics and between role ambiguity and exchange/interchange and coalition tactics (Nonis et al., 1996). In the event of role conflict, applying assertive tactics is necessary to reduce the negative results of role stressors (Nonis et al., 1996). Finally, in the event of role overload, in which the employees do not have the ability to accept additional responsibilities, using passive tactics such as supplication tactic could be effective. The aim of applying these tactics is to prevent accepting additional responsibilities and maintain valuable resources of time and energy. 


\subsubsection{Organizational hierarchy}

Some of the organizational studies investigated impression management tactics inside organizations have specially concentrated on the organization's status and position (Cable \& Judge, 2003; Kacmar et al., 2004; Thacker \& Wayne, 1995); since in most cases, status is associated with organizational hierarchy and according to many scholars and it influences impression management tactics (Ferris \& Judge, 1991).

\subsubsection{Organizational culture}

Based on attraction-selection-attritation (Schlenker, 1987) and based on social information processing theory (Salancik \& Pfeffer, 1978) people keep working in organizations that they are consistent with their organizational culture. Organizational cultures, which support certain impression management tactics could increase the likelihood of applying those tactics in an individual.

\subsection{Personal characteristics}

\subsubsection{Need for success}

Individuals who look for success prefer difficult achievable tasks and look for challenges (Steers \& Braunstein, 1976), try for excellence, and respond well to competition (Jackson, 1989). The results of lots of research indicate that moral people make implementation of social impression and influence such as logical appeal (Cable \& Judge, 2003).

\subsubsection{Need for affiliation}

People look for affiliation wish to be approved by others and cope pace with others' demands. They also show a sincere interest in the feelings of others (Cherrington, 1989). Apparently, existence of these characteristics in an individual could also lead to application of ingratiation tactic.

\subsubsection{Need for independence}

Individuals who wish for independence tend to work more, they often do their job and do not participate in team work (Steers \& Braunstein, 1976). These characteristics help them use certain impression management tactics such as intimidation and threat.

\subsubsection{Need to dominate and control others}

People with this characteristic are interested in giving offers, express ideas, try to convince others, look for active leadership roles, and try to control the events (Steers \& Braunstein, 1976). It seems that these individuals tend to implement ingratiation tactic during their interactions.

\subsubsection{Negative affectivity}

Negative affectivity is related to states and emotional moods such as shyness, anger, and fear (Watson et al., 1988).

\section{The proposed study}

Individuals with high negative affectivity show non-productive work behaviors such as aggressive and insulting behavior towards colleagues, vandalism, theft, and wasting of time (Douglas \& 
Martinko 2001). These findings indicate that individuals with high negative affectivity may implement intimidation and threat tactic. Angriness and being nervous (i.e. a parallel concept to negative affectivity) had a positive and significant relationship with the application of regressive behaviors (Buss et al., 1987). In addition, anger had a negative and significant relationship with organizational citizenship behaviors (Borman et al., 2001). High negative affectivity is normally associated with talking about negative aspects of work with colleagues (Zellars \& Perrewé, 2001). Therefore, people with high negative affectivity make use of supplication tactics (i.e. a form of regression and shrieking responsibility) more, although under different circumstances, they make use of ingratiation tactic less. According to theses interpretations, the following hypothesis can be defined:

Hypothesis 1: Existence of negative affectivity in an individual leads to the application of supplication tactic.

Hypothesis 2: Existence of negative affectivity in an individual leads to the application of intimidation and threat tactic.

Hypothesis 3: Existence of negative affectivity in an individual has a reverse and significant causal relationship with ingratiation tactic.

\subsection{Positive affectivity}

Positive affectivity is a conscious emotional characteristic (Perrewé \& Spector, 2002) which has a positive and significant relationship with positive states and temperaments such as enthusiasm and interest (Watson et al., 1988). In this study 9 emotional dimensions including interest, excitement, strength, self-esteem, assertiveness, being active and energized, inspiration and intuition, accuracy and attention as the dimensions of positive affectivity and considered.

Behavioral specialists have not devoted enough attention to positive affectivity compared with negative one (Perrewé \& Spector, 2002). The reason is because there is not enough data about it. In normal conditions, positive affectivity does not lead to non-productive work behavior. But there is one exception and that is when job satisfaction is low and the period in which an individual is assigned to a job is getting long (Duffy et al., 1998). Positive affectivity has a negative relationship with fatigue (Wright \& Cropanzano, 1998) and a mere relationship with organizational citizenship behaviors (Borman, et al., 2001). In addition, extroversion, which is closely associated with positive affectivity had a positive and significant relationship with organizational citizenship behaviors (Borman et al., 2001), though research findings in this field have been different (Perrewé \& Spector, 2002). However, some people believe that compared with extroversion, positive affectivity has a greater capability in forecasting (Borman et al., 2001). An interview investigated by researchers, emotional stability had a positive and significant relationship with impression management tactics, which were concentrated on others (Van Iddekinge et al., 2007).

It seems that people with high positive affectivity use impression management tactics, which are focused on others such as ingratiation. Extroversion has a positive relationship with argumentation (Buss et al., 1987), inspirational motivation, observance and attention in transformational leadership (Judge \& Bonou, 2000). In addition, there is a close relationship between non-productive work behaviors and application of intimidation and threat tactics. Therefore, it is unlikely that these individuals use tactics of this type. According to the above descriptions, the following hypotheses can be defined:

Hypothesis 4: The existence of positive affectivity in an individual has a reverse causal relationship with the application of supplication tactic. 
Hypothesis 5: The existence of positive affectivity in an individual has a reverse causal relationship with the application of intimidation and threat tactic.

Hypothesis 6: The existence of positive affectivity in an individual leads to the application of ingratiation tactic.

The theoretical model of the present study includes factors that create impression management tactics. Research hypothesis are dealt with in the next section of the research are based on the literature and identify the relationship between affectivity (positive and negative) and the impression management tactics. Causing factors in our theoretical model include positive and negative affectivity. A lot of impression management tactics have been investigated in the literature; however the theoretical framework of the present study intentionally investigates three different tactics (including ingratiation, supplication-, and intimidation and threat) (Bolino \& Turnly, 1999). Each of these tactics represents a kind of behavior, i.e. soft, passive, and aggressive, respectively. Fig. 1 illustrates the theoretical model of the research.

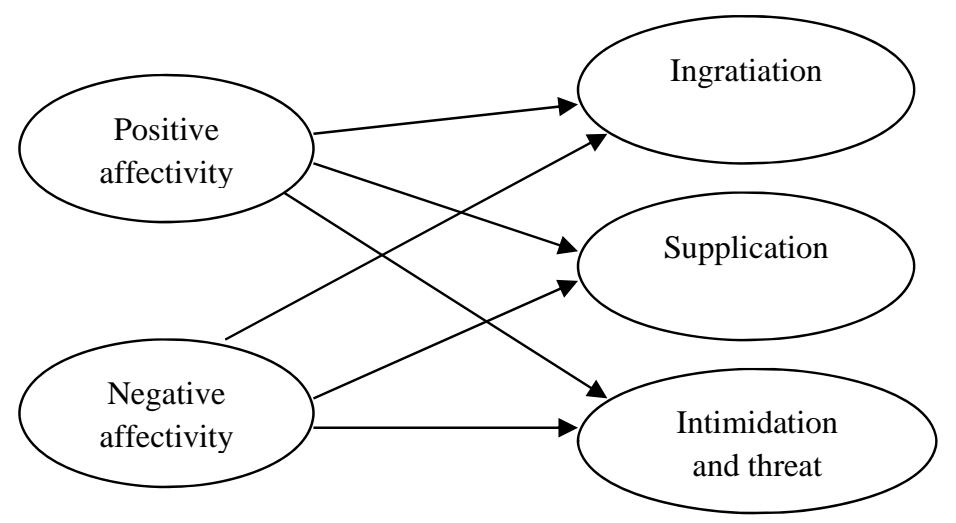

Fig. 1. Causing factors and tactics of impression management (Adopted from Ferris et al., 1999)

\subsection{Research methodology}

Statistical population of the present study includes the employees and staff of the city of Qom's Departments of Education (regions 1,2,3,4 and the headquarters). The abovementioned population consists of people of various combinations regarding age, gender, and education. Statistical sample of the study consisted of 217 individuals based on sample volume and based on the population under investigation and based on Kohen's Table. In this research, multi-stage sampling technique was used. In this way, first of all the city of Qom was geographically divided into four separate regions and the headquarters and then according to these regions and the main districts of each one, 40 individuals were selected by chance from each of these regions.

Measurement tools included: 1) personal information questionnaire (for staff and employees) which includes personal characteristics (age, gender, experience, and educational degrees), 2) scales of positive and negative affectivity, and 3) impression management tactics measurement scale. Scales of positive and negative affectivity include 20 articles, which take approximately 10 words for each emotional dimension describing different feelings and emotions (Watson et al., 1988). The opinions of participants about each of these words are evaluated using a five-point Likert scale. Internal correlation and internal stability (Cronbach's alpha coefficient) which were obtained by the makers of this scale was ranked from 0.86 to 0.90 for positive affectivity and from 0.84 to 0.87 for negative affectivity. Correlation between positive and negative affectivity was always law and reported to be between -0.12 to -0.23 (Watson \& Tellegen, 1988). Each of these affectivities are composed of 
certain articles. For example, positive affectivity consists of articles such as the feeling of self-esteem and pride, assertiveness, passion, and so on; and the negative affectivity was composed of articles such as shyness, fear, irritability, violence, and so on. In order to determine the reliability of the questionnaire, 30 questionnaires were distributed and collected. In this study, Cronbach's alpha for positive and negative affectivity obtained as 0.94 and 0.96 , respectively. The scale used for measuring the impression management tactics has three dimensions (Bolino \& Turnly, 1999).

These dimensions include ingratiation, supplication, and intimidation and threat. Any of these dimensions has got some articles: ingratiation tactic (4 articles), supplication tactic (5 articles), and intimidation and threat tactic (5 articles). Any of these articles were evaluated using the scale (from 15) in which 1 indicates "completely agree" and 5 indicated "completely disagree”. This scale is used for measuring the tactics used by employees in front of their supervisors and colleagues. The respondents indicate the sequence of making use of these tactics in front of their supervisors and colleagues with filling in the blanks. The amounts of Cronbach's alpha for the subscales of ingratiation, supplication, and intimidation and threat were $0.88,0.93$, and 0.88 respectively. Also, factorial validity test of the questionnaire was done using confirmatory factor analysis by means of LISREL software 8.53. The results of confirmatory factor analysis for scales are identified in Tables 1,2 , and 3 .

\section{Table 1}

Positive affectivity measurement model (adopted from Watson et al., 1988)

\begin{tabular}{lcc}
\hline \multicolumn{1}{c}{ Positive affectivity } & Standard coefficient & t-value \\
\hline 1.Feeling of interest and affiliation & 0.46 & 9.31 \\
2.Feeling of excitement & 0.45 & 9.26 \\
3.Feeling of strength & 0.51 & 9.52 \\
4.Feeling of enthusiasm & 0.60 & 9.79 \\
5.Feeling of self- esteem & 0.42 & 9.15 \\
6.Feeling of assertiveness & 0.50 & 9.48 \\
7.Feeling of being active and energized & 0.59 & 9.76 \\
8.Feeling of inspiration and intuition & 0.30 & 8.29 \\
9.Accuracy and attention & 0.44 & 9.26 \\
\hline
\end{tabular}

Table 2

Negative affectivity measurement model (adopted from Watson et al., 1988)

\begin{tabular}{lcc}
\hline Negative affectivity & Standard coefficient & $\mathrm{t}$-value \\
\hline 1.Feeling of panic (suffering and helplessness & 0.52 & 10.10 \\
2.Frustration & 0.28 & 9.57 \\
\hline 3.Feeling of guilt & 0.34 & 9.77 \\
4.Aggressiveness and hostility & 0.32 & 9.71 \\
5.Irritability & 0.30 & 9.63 \\
6.Expecting risk or difficulty & 0.29 & 9.60 \\
7.Shyness and shamefulness & 0.27 & 9.52 \\
8.Feeling of anger & 0.23 & 9.32 \\
9.Feeling of fear and terror & 0.18 & 8.93 \\
10.Feeling of anxiety & 0.20 & 9.13 \\
\hline 11.Impatience and being in hurry & 0.17 & 8.77 \\
\hline
\end{tabular}

The results of LISREL output of charts $(1,2,3)$ indicated that the measurement model of research variables is an appropriate one. The values of chi-squares, RMSEA, and the ration of chi-squares to degrees of freedom were low for all of the three variables while their GFI and AGFA values are above 90\%. Also, all $\mathrm{t}$ values are significant. Totally, these results indicate that the research questionnaires have high reliability and validity. 
Table 3

Impression management tactics measurement model (adopted from Bolino \& Turnly, 1999)

\begin{tabular}{|c|c|c|}
\hline Scales for measuring impression management tactics & efficient & t-value \\
\hline $\begin{array}{l}\text { 1.I pretend not to know much about certain job related issues so that my supervisor lowers his } \\
\text { expectations from me and vest less tasks to me. (ingratiation) }\end{array}$ & 0.11 & 5.69 \\
\hline 2. By showing off in some areas I try to attract their empathy and assistance. (ingratiation) & 0.22 & 8.35 \\
\hline $\begin{array}{l}\text { 3. I act in a way as if I am in need of others' assistance so that I can get help from them. } \\
\text { (ingratiation) }\end{array}$ & 0.28 & 8.88 \\
\hline $\begin{array}{l}\text { 4. In front of others I pretend not to understand certain things so that I can get their assistance } \\
\text { and consultation. (intimidation and threat) }\end{array}$ & 0.22 & 8.28 \\
\hline 5. If others interfere in my job too much, I behave roughly. (intimidation and threat) & 0.08 & 5.37 \\
\hline $\begin{array}{l}\text { 6. I make others understand that if they take me under too much pressure, I can make the } \\
\text { situation rough. (intimidation and threat) }\end{array}$ & 0.18 & 8.24 \\
\hline $\begin{array}{l}\text { 7. In order to do my tasks I sometimes must use intimidation and threat. (intimidation and } \\
\text { threat) }\end{array}$ & 0.21 & 8.64 \\
\hline $\begin{array}{l}\text { 8. Sometimes I use intimidation and threat so that others behave properly. (intimidation and } \\
\text { threat) }\end{array}$ & 0.19 & 8.32 \\
\hline $\begin{array}{l}\text { 9. Sometimes I show interest in the personal lives of my supervisors and colleagues so that I } \\
\text { prove my friendship to them. (supplication) }\end{array}$ & 0.08 & 5.11 \\
\hline $\begin{array}{l}\text { 10. I praise others (my supervisors and colleagues) so that they evaluate me as a lovely } \\
\text { character. (supplication) }\end{array}$ & 0.18 & 8.32 \\
\hline $\begin{array}{l}\text { 11. I voluntarily assist others (my supervisors and colleagues) in their personal issues so that } \\
\text { they will like me. (supplication) }\end{array}$ & 0.16 & 7.76 \\
\hline $\begin{array}{l}\text { 12. I praise others (my supervisors and colleagues) for their success so that I appear a good } \\
\text { character to them. (supplication) }\end{array}$ & 0.27 & 9.18 \\
\hline
\end{tabular}

\section{Data analysis method and research findings}

In order to test the hypotheses, first of all Spearman's Rank Correlation Coefficient test was used for measuring the correlation between the variables by means of SPSS 15 software. Then, the causal relationship between the independent and dependent variables of the study was tested using Structural Equation Modeling by means of LISREL 8.5 software. This is the final step of confirmatory factor analysis which was done for the research scales before, while also determining the validity of the conceptual model by means of Goodness of Fit Index (GFI). As it is illustrated in Fig. 1, the appropriateness of validity and fitness of models is confirmed, because chi-square and RMSEA values are appropriate and the ration of chi-square to degree of freedom is less than 3 and also the values of GFI and AGFA in all of the models are more than 90 percent.

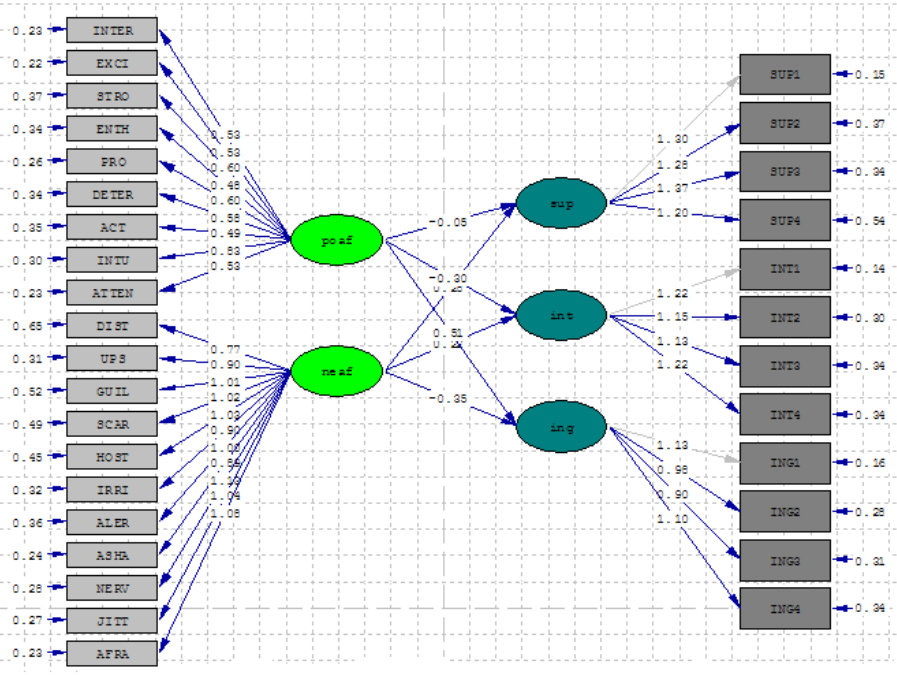

Fig. 1. Structural Equation Modeling (Standardized coefficients) GFI= . 93 AGFI= .91 $1447.51 \mathrm{df}=557 \mathrm{RMSEA}=.063$ 
Ingratiation tactic, intimidation and threat, and supplication are indicated by INGR, INT, and SUP, respectively, while positive and negative affectivity are identified by POAF and NEAF respectively. The effects of negative affectivity on the three tactics are significant and confirmed. In case of positive affectivity, its effects on both tactics of ingratiation and intimidation and threat are confirmed. T values for these 5 items are significant. $t$ values demonstrate that hypotheses $1,2,3,5$, and 6 are confirmed and hypothesis 4 which had anticipated a reverse relationship is confirmed but since the $t$ value is less than 2 it is not significant and is rejected.

\section{Discussion and conclusion}

This paper was an attempt to investigate the relationship between the variable of positive and negative affectivity and the application of impression management tactics, so that it is determined that individuals with certain affectivities use which tactics to enforce their impacts. Research findings have confirmed a positive and significant relationship between the variables of positive affectivity and the application of ingratiation tactic, and between the variables of negative affectivity and the application of supplication- and intimidation and threat tactic and a negative and significant relationship between two variables of negative affectivity and the ingratiation tactic. Investigating the relationship between two variables of positive affectivity and the application of supplication- tactic also indicated a reverse relationship between these two variables.

Results of hypotheses 1 indicate that there is a positive and significant relationship between negative affectivity and the application of supplication- tactic. This finding is partially consistent with the findings of previous findings. For example, in many studies the concept of anger has had a positive and significant relationship with the application of regressive and suppressed behaviors (being moody and sulky), and self-humiliation (feeling degraded) (Buss et al., 1987). These individuals tend to talk about the negative aspects of their workplace (Zellars \& Perrewé, 2001) and thus boast to others about the difficulties of their responsibilities and difficulties of their tasks and seek for others help with a desperate tone. In addition, individuals with high negative affectivity tend to impatience, fear, anxiety, and stress and in emergency and critical situations apply the supplication- tactic due to their lack of self-confidence. Informed and insightful managers must create situations in the company in which political destructive behaviors by the staff is prevented. Political behaviors such as application of supplication- and intimidation and threat tactics are destructive behaviors, because they not only threat the organization, but also the spiritual and mental safety of the individual in long term. Even it is likely that these behaviors affect the personal lives of the individuals and personality disorders appear in them in long-term. On the other hand, hypothesis 4 investigates the relationship between two variables of positive affectivity and the application of supplication- tactic. Testing of this hypothesis demonstrates that there is a reverse relationship between these two variables. Since individuals with high positive affectivity tend to be enthusiastic, strong, interested and having high self-esteem, the application of supplication seems unlikely.

In fact, this hypothesis specifies that in the same way, the existence of negative affectivity in the organization has had a direct relationship with the application of supplication tactics, fostering and expanding the positive affectivities in the organization reduces the likelihood of occurrence of such behaviors. This is an encouraging fact, because human resource managers can foster positive affectivity by adopting appropriate measures and policies and thus reduces the likelihood of occurrence of such behaviors. The first step for such a measure is to analyze the components of positive and negative affectivities and making them practical for specific programs and policies. For instance, if the organization only awards the successful and productive plans, and blame and punish the ineffective ones, then an atmosphere of panic and fear of failure is generated within the organization, which can have destructive effects. The organization must not only appreciate successes, but also failures when it is appropriate. Strong leaders generate the spirit of being active and assertive and they have energized in the organization's members by using the organization's 
mission and its interpretation. The average of negative affectivity in this research was 3.811 in a five point scale, which was greater than the average of positive affectivity, which was 2.96.

Hypothesis 2 investigates the relationship between two variables of negative affectivity and the application of ingratiation tactic. Testing the hypothesis has indicated that there was a negative and significant relationship between these two variables. As it was stated before, due to the tendency to anxiety, aggression, and anger and quick-temper, it seems unlikely that these people apply ingratiation tactic. Hypothesis 5 indicated a positive and significant relationship between two variables of positive affectivity and the application of ingratiation tactic. This hypothesis was also confirmed in the considered significance level. In an interview, which was investigated by the researchers, the emotional stability had a positive and significant relationship with impression management tactics focused on others (for example, praising others) (Van Iddekinge et al., 2007). Unlike individuals with high negative affectivity, individuals with high positive affectivity enjoy high emotional stability and that is why it is natural if these people make use of ingratiation tactic. In addition, Cable and Judge (2003) concluded that individuals who are less angry, apply a wide range of impression management tactics such as inspirational appeals, ingratiation, personal appeals, and exchange/interchange. In addition, Caldwell and Burger (1997) stated that high self-control in the individual had a substantially significance relationship with certain impression management tactics such as rational persuasion. Unlike individuals with high negative affectivity, individuals with high positive affectivity enjoy higher emotional stability and become less angry and thus make use of soft tactics such as ingratiation.

The application of ingratiation tactic by the employees in a moderate manner is generally beneficiary for the organization. However, applying too much of this political behavior within the organization could lead to an atmosphere of distrust and dishonesty and employees' feeling that it is not their work and endeavor, which guarantees their success, but ingratiation and flattery are more useful tools in this regard. Individuals who make use of this tactic moderately are more likely to negotiate, compromise, and cooperate and try to resolve the problems by argumentation and eliminating the challenges. This approach eliminates the conflict and reduces the likelihood of evolution of stressful and threatening situations. Therefore, it is possible to reduce the likelihood of occurrence of such situations by making the necessary conditions for the formation of positive affectivity and eliminating negative affectivity and create an atmosphere for cooperation and intimacy. People with high positive affectivity and low negative affectivity can better dominate the situation and analyze the problems. These people understand the situation well and try not to damage their interests, without making any tensions by being soft and adopting the necessary policies. Therefore, by formulating appropriate programs, management should convince the employees to resolve their problems by means of positive affectivity such as interest, enthusiasm, and self-esteem. By resorting to negative affectivity such as anger, irritability, and anxiety, not only the problems remain unsolved, but also, in some cases, the circumstances turn even worse. In fact, management should make the necessary selfawareness in the employees.

Hypothesis 3 investigates the relationship between two variables of negative affectivity and the application of intimidation and threat tactic. This relationship was significant in the considered significance level. On the other hand, in hypothesis 6 investigation of the relationship between the two variables indicated that there was a negative and significant relationship between the two variables of positive affectivity and application of threat and intimidation tactic. These finding are consistent with the results of the studies that indicate individuals with high negative affectivity make great deals of stress for themselves (Zellars \& Perrewé, 2001). Individuals with high negative affectivity, due to tendency to behaviors such as aggression and hostility, irritability, anger, selfcontrol, self-awareness, and low emotional stability reveal harsh and aggressive behaviors, and their aggressiveness demonstrated via tactics such as intimidation and threat. Unlike these individuals, people with high positive affectivity due to high emotional stability and tendency to enthusiasm and 
being interested, instead of applying such aggressive tactics tend to use soft tactics such as ingratiation. These individuals due to their high self-control analyze the situation and instead of using aggressive and emotional behaviors, handle the situation well. In addition, extraversion has a close association with positive affectivity (Buss et al., 2001), inspirational motivation, and observance and attention in transformational leadership (Judge \& Bonou, 2000), so it is unlikely that these individuals use tactics such as threat and intimidation. Tactics such as intimidation and threat are destructive for the organization and management must attempt to prevent their occurrence by identifying the factors that affect them. As we stated earlier, management can improve the situation by analyzing the negative and positive affectivities and leading them into the optimum direction. We need to understand that in view of a lot of organizational behavior scholars, political behaviors can be subject to change and can improve via teaching, observing and control, and modeling the behaviors (Ferris, Davidson \& Perrewé, 2005; Ferris et al., 2007). In cases when individuals have high negative affectivity, people have a lower understanding of each other and pave the way for the creation of tension and conflict. Management must decrease the likelihood of demonstrating such behaviors by fostering the positive affectivity such as enthusiasm, interest, self-esteem, and so on among employees and create a positive atmosphere for cooperation and tolerance of various tastes. Maybe the responsibility of management in this field has turned even heavier by the entrance of females into the labor and the increasing diversity of workforce.

According to the research findings, the following strategies are proposed:

Training the employers by human resource manager, in order to make them familiar with moderate and reasonable behaviors in the organization and make them observe the moral standards. In addition, employers must know where the borderlines of applying these tactics are, because going to extremes in applying these behaviors will bring about losses by itself. Then, optimum conditions must be created in to organization so that destructive political behaviors are prevented. Optimum and satisfactory conditions create desirable emotions and feelings in the staff, making them apply softer and more reasonable political tactics in the organization. In addition to training the staff in the general level, specialized advice and assistance programs must be devised for employees with low selfawareness. Rules and regulations must be developed that clearly determines the border of behaviors and actions, because these rules can prevent many political behaviors from diversions. For example, transparency and clarity in performance evaluation can prevent the division of political behaviors such as ingratiation.

Finally, it should be noted that it is necessary to do more studies on the impression management tactics as an important issue in organizations. Besides, this issue is not well identified in Iran and just a few papers have dealt with it. Therefore, the following proposals are offered for future studies: investigating the organizational hierarchy by applying impression management tactics; investigating the relationship between organizational culture and the application of certain impression management tactics (impression management tactics are more likely to form in what cultures), investigating the relationship between needs of individuals and application of certain impression management tactics.

\section{References}

Beehr, T. A. 1995. Psychological stress in the workplace. London, UK: Routledge.

Bolino, M. C., \& Turnly, W.H. (1999). Citizenship and impression management: Good soldiers or good actors? Academy of Management Review, 24: 82-98.

Bolino, M. C., \& Turnley, W. H. (2003). More than one way to make an impression: Exploring profiles of impression management. Journal of Management, 29, 141-161.

Borman, W. C., Penner, L. A., Allen, T. D., \& Motowidlo, S. J. (2001). Personality predictors of citizenship performance. International Journal of Selection and Assessment, 9, 52-69.

Bozeman, D. P., \& Kacmar, K.M. (1997). Acybernetic model of impression management processes in organizations. Organizational Behavior and Human Decision Processes, 69, 9-30. 
Buss, D., Gomes, M., Higgins, C. A., \& Lauterbach, K. (1987). Tactics of manipulation. Journal of Personality and Social Psychology, 52: 1219-1229.

Cable, D. M., \& Judge, T. M. (2003). Manager's upward influence tactic strategies: The role of manager personality and supervisor leadership style. Journal of Organizational Behavior, 24, 197214.

Caldwell, D. F., \& Burger, J. M. (1997). Personality and social influence strategies in the workplace. Personality and Social Psychology Bulletin, 23(10), 1003-1012.

Cherrington, D. J. (1989). Need theories of motivation. In R. M. Steers \& L. W. Porter (Eds.), Motivation and work behavior: 31-44. New York: McGraw-Hill.

Christiansen, N., Villanova, P., \& Mikulay, S. (1997). Political influence compatibility: Fitting the person to the climate. Journal of Organizational Behavior, 18(6), 709-730.

Costa, P. T., \& McCrae, R. R. (1992). Revised NEO Personality Inventory (NEO-PI-R) and NEO

Five-Factor Inventory professional manual. Odessa, FL: Psychological Assessment Resources.

Douglas, S. C., \& Martinko, M. J. (2001). Exploring the role of individual differences in the prediction of workplace aggression. Journal of Applied Psychology, 86, 547-559.

Duffy, M. K., Ganster, D. C., \& Shaw, J. D. (1998). Positive affectivity and negative outcomes: The role of tenure and job satisfaction. Journal of Applied Psychology, 83, 950-959.

Fandt, P. M., \& Ferris, G. R. (1990). The management of information and impressions: When employees behave opportunistically. Organizational Behavior and Human Decision Processes, 45, 140-158.

Ferris, G. R., Russ, G. S., \& Fandt, P. M. (1989). Politics in organizations. In R. A. Giacalone \& P. Rosenfeld (Eds.), Impression management in the organizations: 143-170. Hillsdale, NJ: Erlbaum.

Ferris, G. R., \& Judge, T. A. (1991). Personnel/human resources management: A political influence perspective. Journal of Management, 17, 447-488.

Ferris, G. R., Dulebohn, J. H., Frink, D. D., George-Falvy, J., Mitchell, T. R., \& Matthews, L. M. (1997). Job and organizational characteristics, accountability and employee influence. Journal of Managerial Issues, 9(2), 162-175.

Ferris, G. R., Hochwarter, W. A., Douglas, C., Blass, F. R., Kolodinsky, R. W., \& Treadway, D. C. (2002). Social influence processes in organizations and human resources systems. Research in Personnel and Human Resources Management, 21, 65-127.

Goffman, E. (1959). The presentation of self in everyday life. Garden City, NY: Bantam Books.

Jackson, D. N. (1989). Personality research form manual. (3 ${ }^{\text {rd }}$ ed.). Port Huron, MI: Research Psychologists Press, Inc.

Jackson, S. E., \& Schuler, R. S. (1985). A meta-analysis and conceptual critique of research on role ambiguity and role conflict in work settings. Organizational Behavior and Human Decision Processes, 36, 16-78.

Jones, E. E., \& Pittman, T. S. (1982). Toward a general theory of strategic selfpresentation. Psychological perspectives on the self, 1, 231-262.

Judge, T. A., \& Bretz, R. D. (1994). Political influence behavior and career success. Journal of Management, 20, 43-65.

Kacmar, K. M., Carlson, D. S., \& Bratton, V. K. (2004). Situational and dispositional factors as antecedents of ingratiatory behaviors in organizational settings. Journal of Vocational Behavior, 65, 309-331.

Kipnis, D., Schmidt, S. M., \& Wilkinson, I. (1980). Intraorganizational influence tactics: Explorations in getting one's way. Journal of Applied Psychology, 65(4), 440-452.

Kipnis, D., \& Schmidt, S. M. 1988. Upward-influence styles: Relationship with performance evaluations, salary, and stress. Administrative Science Quarterly, 33, 528-542.

Kristof-Brown, A. L., Barrick, M. R., \& Franke, M. (2002). Applicant impression management : Dispositional influences and consequences for recruiter perceptions of fit and similarity. Journal of Management, 28(1), 27-46. 
Leary, M. R., \& Kowalski, R. M. (1990). Impression management: A literature review and two component model. Psychological Bulletin, 107(1), 34-47.

Mayes, B. T., \& Ganster, D. C. (1988). Exit and voice: A test of hypotheses based on fight/flight responses to job stress. Journal of Organizational Behavior, 9(3), 199-21.

Mowday, R. T. (1978). The exercise of upward influence in organizations. Administrative Science Quarterly, 23: 137-156.

Nonis, S. A., Sager, J. K., \& Kumar, K. (1996). Salespeople's use of upward influence tactics (UITs) in coping with role stress. Academy of Marketing Science, 24(1), 44-56.

Örtqvist, D., \& Wincent, J. 2006. Prominent consequences of role stress: A meta-analytic review. International Journal of Stress Management, 13(4), 399-422.

Perrewé, P. L., \& Spector, P. E. (2002). Personality research in the organizational sciences. Research in Personnel and Human Resources Management, 21, 1-64.

Rizzo, J., House, R. J., \& Lirtzman, S. I. (1970). Role conflict and ambiguity in complex organizations. Administrative Science Quarterly, 15, 150-163.

Rosenfeld, P. R., Giacalone, R. A., \& Riordan, C. A. (1995). Impression management in organizations: Theory, measurement, and practice. New York: Routledge.

Salancik, G. R., \& Pfeffer, J. (1978). A social information processing approach to job attitudes and task design. Administrative Science Quarterly, 23, 224-253.

Schlenker, B. R. (1980). Impression management: The self-concept, social identity, and interpersonal relations. Monterey, CA: Brooks/Cole.

Schneider, B. (1987). The people make the place. Personnel Psychology, 40, 437-453.

Seashore, S. E., Lawler, E. E., Mirvis, P., \& Cammann, C. (1982). Observing and measuring organizational change: A guide to field practice. New York, NY: Wiley.

Steers, R. M., \& Braunstein, D. N. (1976). A behaviorally-based measure of manifest needs in work settings. Journal of Vocational Behavior, 9, 251-266.

Tepper, B. J., Duffy, M. K., \& Shaw, J. D. (2001). Personality moderators of the relationship between abusive supervision and subordinates' resistance. Journal of Applied Psychology, 86, 974-983.

Tett, R. P., \& Gutterman, H. A. (2000). Situation trait relevance, trait expression, and crosssituational consistency: Testing a principle of trait activation. Journal of Research in Personality, 34, 397423.

Tett, R. P., \& Burnett, D. D. (2003). A personality trait-based interactionist model of job performance. Journal of Applied Psychology, 88, 500-517.

Thacker, R. A., \& Wayne, S. J. (1995). An examination of the relationship between upward influence tactics and assessments of promotability. Journal of Management, 21(4), 739-756.

Van Iddekinge, C. H., McFarland, L. A., \& Raymark, P. H. (2007). Antecedents of Impression Management Use and Effectiveness in a Structured Interview. Journal of Management, 33(5), 752773.

Vecchio, R. P., \& Sussmann, M. (1991). Choice of influence tactics: Individual and organizational determinants. Journal of Organizational Behavior, 12, 73-80.

Watson, D., Clark, L. A., \& Tellegen, A. (1988). Development and validation of brief measures of positive and negative affect: The PANAS scales. Journal of Personality and Social Psychology, 6, 1063-1070.

Wayne, S. J., \& Ferris, G. R. (1990). Influence tactics, affect, and exchange quality in supervisorsubordinate interactions: A laboratory experiment and field study. Journal of Applied Psychology, 75, 487-499.

Wright, T. A., \& Cropanzano, R. (1998). Emotional exhaustion as a predictor of job performance and voluntary turnover. Journal of Applied Psychology, 83, 486-493.

Zellars, K. L., \& Perrewé, P. L. (2001). Affective personality and the content of emotional social support: Coping in organizations. Journal of Applied Psychology, 86, 459-467. 